\title{
Fish wariness is a more sensitive indicator to changes in fishing pressure than abundance, length or biomass
}

\author{
Jordan S. Goetze (iD , 1,2,8,10 Fraser A. Januchowski-Hartley, ${ }^{3,9}$ Joachim Claudet, ${ }^{4,5}$ \\ Tim J. Langlois, ${ }^{1,2}$ Shaun K. Wilson, ${ }^{1,6}$ and Stacy D. Jupiter ${ }^{7}$ \\ ${ }^{1}$ The UWA Oceans Institute, The University of Western Australia, 35 Stirling Highway, Crawley, Western Australia 6009 Australia \\ ${ }^{2}$ School of Biological Sciences, The University of Western Australia, 35 Stirling Highway, \\ Crawley, Western Australia 6009 Australia \\ ${ }^{3}$ Department of Geography, College of Life and Environmental Sciences, University of Exeter, Exeter, United Kingdom \\ ${ }^{4}$ National Center for Scientific Research, CRIOBE, USR 3278 CNRS-EPHE-UPVD, 66860 Perpignan, France \\ ${ }^{5}$ Labortaoire d'Excellence CORAIL, France \\ ${ }^{6}$ Department of Parks and Wildlife, Marine Science Program, Kensington, Western Australia 6151 Australia \\ ${ }^{7}$ Wildlife Conservation Society, Melanesia Program, 11 Ma'afu Street, Suva, Fiji \\ ${ }^{8}$ Department of Environment and Agriculture, Curtin University, Bentley Campus, Western Australia 6485 Australia \\ ${ }^{9}$ UMR 248 MARBEC/250 ENTROPIE, Institut de recherche pour le développement, Batiment 24, \\ Université de Montpeller 2 34095, Montpellier cedex France
}

\begin{abstract}
Identifying the most sensitive indicators to changes in fishing pressure is important for accurately detecting impacts. Biomass is thought to be more sensitive than abundance and length, while the wariness of fishes is emerging as a new metric. Periodically harvested closures (PHCs) that involve the opening and closing of an area to fishing are the most common form of fisheries management in the western Pacific. The opening of PHCs to fishing provides a unique opportunity to compare the sensitivity of metrics, such as abundance, length, biomass and wariness, to changes in fishing pressure. Diver-operated stereo video (stereo-DOV) provides data on fish behavior (using a proxy for wariness, minimum approach distance) simultaneous to abundance and length estimates. We assessed the impact of PHC protection and harvesting on the abundance, length, biomass, and wariness of target species using stereo-DOVs. This allowed a comparison of the sensitivity of these metrics to changes in fishing pressure across four PHCs in Fiji, where spearfishing and fish drives are common. Before PHCs were opened to fishing they consistently decreased the wariness of targeted species but were less likely to increase abundance, length, or biomass. Pulse harvesting of PHCs resulted in a rapid increase in the wariness of fishes but inconsistent impacts across the other metrics. Our results suggest that fish wariness is the most sensitive indicator of fishing pressure, followed by biomass, length, and abundance. The collection of behavioral data simultaneously with abundance, length, and biomass estimates using stereoDOVs offers a cost-effective indicator of protection or rapid increases in fishing pressure. StereoDOVs can rapidly provide large amounts of behavioral data from monitoring programs historically focused on estimating abundance and length of fishes, which is not feasible with visual methods.
\end{abstract}

Key words: artisanal fisheries; catch efficiency; compliance; conservation; customary management; fish behavior; fisheries management; flight initiation distance.

\section{INTRODUCTION}

Fishing is the most widespread, exploitative activity in our oceans. To understand its impacts on marine communities, it is important to identify the most sensitive indicators of fishing pressure (Nash and Graham 2016). In contemporary fisheries management and conservation, length and biomass are considered to be the first metrics to respond to protection from fishing (Claudet et al.2006) and may detect responses that are not apparent in abundance data (McClanahan et al. 2007). Recent studies have identified impacts of fishing on the behavior of targeted species (Alós et al. 2012, 2015,

Manuscript received 29 April 2016; revised 19 November 2016; accepted 10 January 2017. Corresponding Editor: Olaf Jensen.

${ }^{10}$ E-mail: gertza@gmail.com
Januchowski-Hartley et al. 2015), yet the sensitivity of behavioral relative to traditional metrics of changes in fishing pressure is unknown.

Fisheries management can alleviate the impacts of overfishing (MacNeil et al. 2015), with mounting evidence that strategies which build upon long-standing cultural practice can achieve effective compliance and conservation outcomes (McClanahan et al. 2006a, Cinner et al. 2012). Spearfishing is a commonly used fishing strategy that has been shown to increase the wariness of targeted species (Feary et al. 2011, Januchowski-Hartley et al. 2011) and across the tropical western Pacific, some customary management strategies (e.g., temporal closures) are aimed at reducing wariness in order to maximize catches (Cinner et al. 2006, Macintyre and Foale 2007, Cohen and Foale 2013). These traditions have blended with conventional approaches to marine resource management, manifesting 
in "periodically harvested closures" (PHCs), with variable harvest regimes that make it difficult to systematically assess their value to fisheries management (Cohen and Foale 2013, Goetze et al. 2016).

Fisheries benefits from temporal or rotational closures through the build-up of abundance and biomass have primarily been demonstrated for sessile or sedentary invertebrates (e.g., Hart 2003, Valderrama and Anderson 2007, Plagányi et al. 2015). While such benefits are predicted for reef fish (De Klerk and Gatto 1981, Game et al. 2009), these have only been demonstrated in a few cases (Cinner et al. 2006, Bartlett et al. 2009, Jupiter et al. 2012, Goetze et al. 2016). Traditional community closures often involve short closure times (i.e., $100 \mathrm{~d}$ in Fiji), which may coincide with the time needed to make fish less wary to spearfishers (e.g., Januchowski-Hartley et al. 2014), but shorter than the time needed to produce significant increases in abundance, length, or biomass (McClanahan et al. 2007). To adequately assess whether PHCs are capable of providing fisheries benefits, in the short-term through increased catch efficiency and in the long-term through increased biomass, length, or abundance, it is important to expand assessments beyond abundance, length and biomass data.

Flight initiation distance (FID) is a behavioral response used as a measure of prey wariness in terrestrial and aquatic systems (Ydenberg and Dill 1986, Blanchard et al. 1991, Stankowich and Blumstein 2005). FID in fish has been shown to be influenced by prior experience where prey learn and adjust their response based on the risk posed by a predator (Brown 2003), with FID increasing as risk increases (Gotanda et al. 2009). For example, on coral reefs, FID of fish targeted by spearfishers (predators) is higher in areas open to fishing than in permanently closed areas (Gotanda et al. 2009, Januchowski-Hartley et al. 2015) or customary closures(Feary etal.2011, JanuchowskiHartley et al. 2014). Customary closures have been observed to reduce FID to an extent that is likely to increase catchability for surgeonfish (Acanthuridae) within six months of closure, an effect lost in as little as three days when reopened to fishing (Januchowski-Hartley et al. 2014). Individual wariness is also associated with body size, with larger individuals and species often showing greater wariness (Stankowich and Blumstein 2005). This has been observed in coral reef fishes (Gotanda et al. 2009, Feary et al. 2011, Januchowski-Hartley et al. 2015), where larger fish are often preferentially targeted (Dulvy et al. 2004, Graham et al. 2005). Thus, the relationship between size and wariness is expected to be less pronounced for targeted species in areas closed to fishing. Behavioural research of fishes can be constrained by the time required for FID data collection, which can disturb other fishes, potentially biasing future data acquisition.

The opening and closing of PHCs to fishing provides a unique opportunity to compare the sensitivity of different metrics to changes in fishing pressure. Diver-operated stereo video (stereo-DOV) can provide highly accurate estimates of fish length and position relative to the camera system (Harvey et al. 2004) and is one of the most effective methods for detecting harvest impacts on targeted species within PHCs (Goetze et al. 2015). Moreover, the distance between the fish and the camera system at the closest point, the minimum approach distance (MAD), potentially provides a useful measure of fish wariness that has been previously used to compare the behavioral response of fish toward divers (Lindfield et al. 2014). Unlike FID, MAD estimates can be collected for every individual encountered, simultaneously with abundance, length, and biomass surveys, resulting in rapid and extensive replication without altering field protocols. Therefore, using stereo-DOV may alleviate several of the constraints associated with collecting FID data, while allowing comparisons with other commonly used metrics.

We collected abundance, length, biomass, and wariness data, using stereo-DOV, inside and outside of four PHCs in Fiji before and after harvest events. We assessed the ability of PHCs to provide short-term fisheries benefits, by increasing fish abundance, length, and biomass, and/or decreasing the wariness of targeted species and examined how the opening of PHCs for harvest events affects these metrics. We predicted that: (1) fish wariness will be more sensitive to changes in fishing pressure than abundance, length and biomass; (2) wariness will increase with fish length; (3) the wariness of larger targeted species will be lower in PHCs than in areas open to fishing; and (4) the wariness of larger targeted species in PHCs will increase following harvest events.

\section{Materials And Methods}

\section{Study area}

Surveys were carried out at reefs adjacent to four villages on Koro (Nakodu, Tuatua) and Ovalau islands (Nauouo, Natokalau), Fiji, in 2013. Each village had a PHC under a different management regime (Table 1). PHCs had been established for 3-7 yr prior to surveys, though the frequency of prior harvests and level of compliance varied. Surveys were carried out immediately before and after harvests that lasted between 1 and $4 \mathrm{~d}$ and involved spearfishing and/or fish drives into gill nets. All historical harvest events were reported by key informants to have been of similar intensity to those presented here. Fisheries at each village were smallscale and artisanal, with the most common methods including spearguns/Hawaiian slings, gill nets, or hook and line (Cakacaka et al. 2010), however, the intensity of fishing pressure varied between locations (Table 1). The extent of fishing in areas outside of PHCs was ranked on a two-point scale (high or low), that considered the number of locally operated boats within a village, the number of boats from outside the village observed in the fishing area on a weekly basis, the density of fishers per square kilometer, and fishing methods used. Highly vulnerable species (including large predatory reef fish) have been depleted across our study locations (Goetze et al. 2016), suggesting the influence of natural predators on fish wariness is relatively low and consistent across villages. 
TABLE 1. Information on periodic harvest closure (PHC) characteristics, fishing grounds, harvests, and targeted species across the four villages.

\begin{tabular}{|c|c|c|c|c|}
\hline Characteristics & Nakodu & Tuatua & Natokalau & Nauouo \\
\hline \multicolumn{5}{|l|}{ PHC and fishing ground information } \\
\hline Size $\left(\mathrm{km}^{2}\right)$ & 0.73 & 1.34 & 2.17 & 3.69 \\
\hline Habitat & lagoon $(1-3 \mathrm{~m})$ & $\begin{array}{l}\text { coastal fringing } \\
\text { reef slope } \\
(5-8 \mathrm{~m})\end{array}$ & lagoon $(1-3 \mathrm{~m})$ & $\begin{array}{l}\text { back reef slope } \\
\quad(5-8 \mathrm{~m})\end{array}$ \\
\hline Year Est. & 2010 & 2005 & 2006 & 2010 \\
\hline Compliance & high & high & high & low \\
\hline Fishing pressure outside & low & low & high & high \\
\hline \multicolumn{5}{|l|}{ Harvest information } \\
\hline Fishing method & $\begin{array}{l}\text { spearfishing and } \\
\text { fish drive }\end{array}$ & $\begin{array}{l}\text { spearfishing and } \\
\text { fish drive }\end{array}$ & $\begin{array}{l}\text { spearfishing and } \\
\text { fish drive }\end{array}$ & spearfishing \\
\hline Historical harvest regime & $\begin{array}{l}\text { none since } \\
\text { creation }\end{array}$ & $\begin{array}{l}\text { every } 3 \text { months } \\
\text { for several } \\
\text { years prior to } \\
\text { study }\end{array}$ & $\begin{array}{l}\text { once in } 2011 \text { and } \\
2012\end{array}$ & $\begin{array}{l}\text { once in } 2011 \text { and } \\
2013\end{array}$ \\
\hline Harvest duration (d) & 4 & 1 & 2 & 3 \\
\hline Harvest intensity $\left(\mathrm{h} / \mathrm{km}^{2}\right)$ & 1271.60 & 50.1 & 94.3 & 39.9 \\
\hline Harvest efficiency (fish person/h) & 3.7 & 2.93 & 3.38 & 2.44 \\
\hline Time closed before previous harvest (yr) & 3 & 0.25 & 1 & 0.08 \\
\hline Focal targeted species & $\begin{array}{l}\text { Chlorurus } \\
\text { spilurus (118), } \\
\text { Scarus rivulatus } \\
\text { (7), Halichoeres } \\
\text { hortulanus (14) }\end{array}$ & $\begin{array}{l}\text { Chlorurus } \\
\text { spilurus (1), } \\
\text { Scarus niger } \\
\text { (11), Scarus } \\
\text { schlegeli (22) }\end{array}$ & $\begin{array}{l}\text { Chlorurus } \\
\text { spilurus (4), } \\
\text { Scarus schlegeli } \\
\text { (9), Scarus } \\
\text { rivulatus (6) }\end{array}$ & $\begin{array}{l}\text { Chlorurus } \\
\text { spilurus (3), } \\
\text { Scarus schlegel } \\
\text { (2), Scarus } \\
\text { rivulatus (1) }\end{array}$ \\
\hline
\end{tabular}

Notes: For habitat, depth is given in parentheses. Year Est., year established. For species, number caught is shown in parentheses.

\section{PHC and harvest information}

All PHCs were relatively large $\left(0.73-3.14 \mathrm{~km}^{2}\right)$ compared to the median for Melanesia $\left(1 \mathrm{~km}^{2}\right.$; Govan et al. 2009), and varied across habitat, depth, and size of local fishing ground (Table 1). Compliance levels were based on surveys with village spokespersons, who rated compliance as low (frequent breaches of rules), moderate (occasional breaches), or high (infrequent breaches). To estimate fishing pressure during harvest events (harvest intensity), we recorded the gear, area fished, time, number of fishers, and their catch (length, abundance, and species) during each PHC harvest. Harvest intensity was calculated as the total number of fisher hours per $\mathrm{km}^{2}$ of PHC.

\section{Sampling design}

We sampled between three and five sites inside each of the PHCs and six sites open to regular fishing (three on each side of each PHC) within the local community's fishing ground. Sites were separated by a minimum of $300 \mathrm{~m}$. At each site, six $5 \mathrm{~m}$ by $50 \mathrm{~m}$ belt transects separated by $10 \mathrm{~m}$ were completed, following (Shedrawi et al. 2014). Sampling was conducted $1-2 \mathrm{~d}$ before the opening of each PHC and $1-2 \mathrm{~d}$ after the harvest. These four treatments were termed PHC before, open before, PHC after, and open after.

\section{Sampling technique}

Stereo-DOVs were used to collect abundance, length, and MAD simultaneously. At each site, one person operated the stereo-DOV system using SCUBA, with a second diver following at least $10 \mathrm{~m}$ behind to avoid influencing fish in front of the camera system. Two alternating dive teams were used to provide greater surface intervals, however, the same two experienced divers operated the stereo-DOV throughout the study and sites were allocated randomly between teams. Both divers used the same stereo-DOV system, wore a black wetsuit and dive gear, and used the same cylinders throughout the survey. The two stereo-DOV operators initially trained as a buddy pair in order to standardize swimming speed. Diver 1 took on average $2 \mathrm{~min}$ and $28 \mathrm{~s}$ to complete each $50 \mathrm{~m}$ transect $(n=246, \mathrm{SE}=0.91 \mathrm{~s})$, while diver 2 took an average of 2 min and $26 \mathrm{~s}(n=228, \mathrm{SE}=1.13 \mathrm{~s})$, suggesting swimming speed was comparable. A relatively slow-approaching diver has been shown to mimic the flight cue caused by a spear-fisher approaching prey, with no influence of spear gun presence on FID (JanuchowskiHartley et al. 2012). This suggests that the cue for avoidance behavior here is a combination of the stereo-DOV (which is held out in front) and the diver, which were both consistent in color, size, shape, and approach speed. Januchowski-Hartley et al. (2012) found no significant influence of diver type (SCUBA vs. free-diving) on FID, suggesting that the minor inconsistencies in this study (i.e., two different people operating the stereo-DOV) are unlikely to have resulted in observer bias.

Biomass was calculated from length estimates using the standard length-mass equations and values from FishBase (Froese and Pauly 2015), preferentially selected from sites closest to Fiji (Jupiter and Egli 2011). Our stereo-DOV systems used two Canon high-definition 
cameras mounted $0.7 \mathrm{~m}$ apart on a base bar inwardly converged at $7^{\circ}$ to provide a standardized field of view from 0.5 to $8 \mathrm{~m}$ Camera systems were built and purchase from: http://www.seagis.com.au/hardware.html. Stereovideo imagery was calibrated using the program CAL (program available online) ${ }^{11}$, following the procedures outlined by Harvey and Shortis (1998). This enabled measurements of fish length, the distance to (range) and angle of the fish from the center of the camera, and standardization of the area surveyed. Individuals further than $8 \mathrm{~m}$ in front (determined by the minimum visibility) or $2.5 \mathrm{~m}$ to the left or right of the stereo-DOV system were excluded. Out of the 4522 individuals observed across all focal species (Table 1), only $0.42 \%$ (19) were observed at distances greater than $8 \mathrm{~m}$ and were all $<40 \mathrm{~cm}$ in length suggesting this cut off did not bias assessments.

Video analysis. - Pairs of videos from the stereo-DOV systems were viewed in the program EventMeasure (see footnote 9). Standard procedures for abundance and identification were followed (Goetze et al. 2015), and data were extracted from EventMeasure and cleaned following (Langlois et al. 2015). To collect MAD data, the fork length for each fish was measured when the fish was at the closest point to the camera and this distance was automatically computed by EventMeasure. If a length measurement could not be made when the fish was at the closest point (i.e., was partly obscured or at a severe angle), a "3D point" was made, which only requires one common point to be located on each stereo pair to calculate distance. The $3 \mathrm{D}$ points were made as close to the center of the fish as possible to match the way that distance estimates are calculated when a length measurement is made (which is essentially a 3D point at the center of the length estimate). This distance was then entered into the original length measurement to give a MAD for every individual measured. The angle of the fish from the center of the stereo-DOV ranged from $0^{\circ}$ to $40^{\circ}$ and linear regression showed no evidence of a relationship with the obliqueness of approach (angle) and MAD $\left(R^{2}=0.0012, \mathrm{SE}=0.037\right)$.

\section{Species selection}

A total of 162 species were caught during harvests. From each village, the three most abundant species from the stereo-DOV surveys that were caught during the harvest and historically targeted by Fijian fishers (Jennings and Polunin 1996b) were pooled as "targeted species." Due to the large spatial scale of the study, this resulted in different species being examined across villages, though the bullethead parrotfish (Chlorurus spilurus) appears in all analyses of "targeted species" (Table 1). The threespot wrasse (Halichoeres trimaculatus) was the only abundant non-target species with a suitable size range for analyses and was limited to individual village analysis. Fish less than $8 \mathrm{~cm}$ were removed

\footnotetext{
${ }^{11}$ http://www.seagis.com.au/software_overview.html
}

from the analyses, as their length could not be measured accurately over the full range ( $8 \mathrm{~m}$; Harvey et al. 2010). All focal species were reef associated and were $<40 \mathrm{~cm}$, suggesting they have small home ranges (Nash et al. 2015). Indeed the largest and most common target species were parrotfish, which have been shown to utilize small patches of coastline (between 0.2 and $1.6 \mathrm{~km}$; Meyer et al. 2010), making it unlikely that movement of fish across PHCs boundaries has influenced our results, given sampling was completed in each village over such a small time scale (1-2 d).

\section{Data analysis}

To account for variation both within and among the different species and villages a meta-analytical approach was used (Gurevitch and Hedges 1999, Osenberg et al. 1999) to model the impact of each PHC and harvest event on the wariness (MAD), abundance, length, and biomass of targeted species and to compare the sensitivity of the metrics to changes in fishing pressure. Log-ratio effect sizes and confidence intervals were used to quantify proportionate change across all metrics, and account for variation in the focal species and study locations (Hedges et al. 1999).

Wariness (MAD).-Linear models were used to assess the relationships between MAD (m) and fork length (cm) across the PHC before, open before, PHC after, and open after surveys (Fig. 1a). Information on samples size and the parameters for each linear model are provided in Data $\mathrm{S} 1$. In areas open to fishing a relatively steep slope is expected, where larger fish targeted by fishers have a greater wariness compared to smaller fish. In PHCs, we expect this slope to decrease as a result of lower wariness in the larger, protected fishes. However, a decrease in slope could also be caused by an increase in wariness of smaller fishes. Thus, to compare the linear relationship of MAD and fish length between PHCs and open areas and distinguish between impacts to small and large fishes, the slope (difference in MAD between large and small fish), and the intercept (difference in MAD for fish too small to target) are required. Similarly, effect sizes comparing slopes and intercepts are needed to assess the impacts of harvest events, because we would expect a greater impact on MAD and wariness of larger fish (due to preferential targeting).

For each village $i$, the slope effect size before the harvest, $m E_{b, i}$, was calculated as the log-ratio of the slope in the PHC before, $\beta_{P b, i}$, to the slope in the open before the harvest, $\beta_{O b, i}$, while the slope effect size after the harvest $m E_{a, i}$, was calculated as the log-ratio of the slope in the PHC after, $\beta_{P a, i}$, to the slope in the open after the harvest, $\beta_{O a, i}$ (see Fig. 1a for conceptual diagram)

$$
m E_{b, i}=\ln \left(\frac{\beta_{\mathrm{Pb}, \mathrm{i}}}{\beta_{\mathrm{Ob}, \mathrm{i}}}\right) \text { and } m E_{a, i}=\ln \left(\frac{\beta_{\mathrm{Pa}, \mathrm{i}}}{\beta_{\mathrm{Oa}, \mathrm{i}}}\right) .
$$




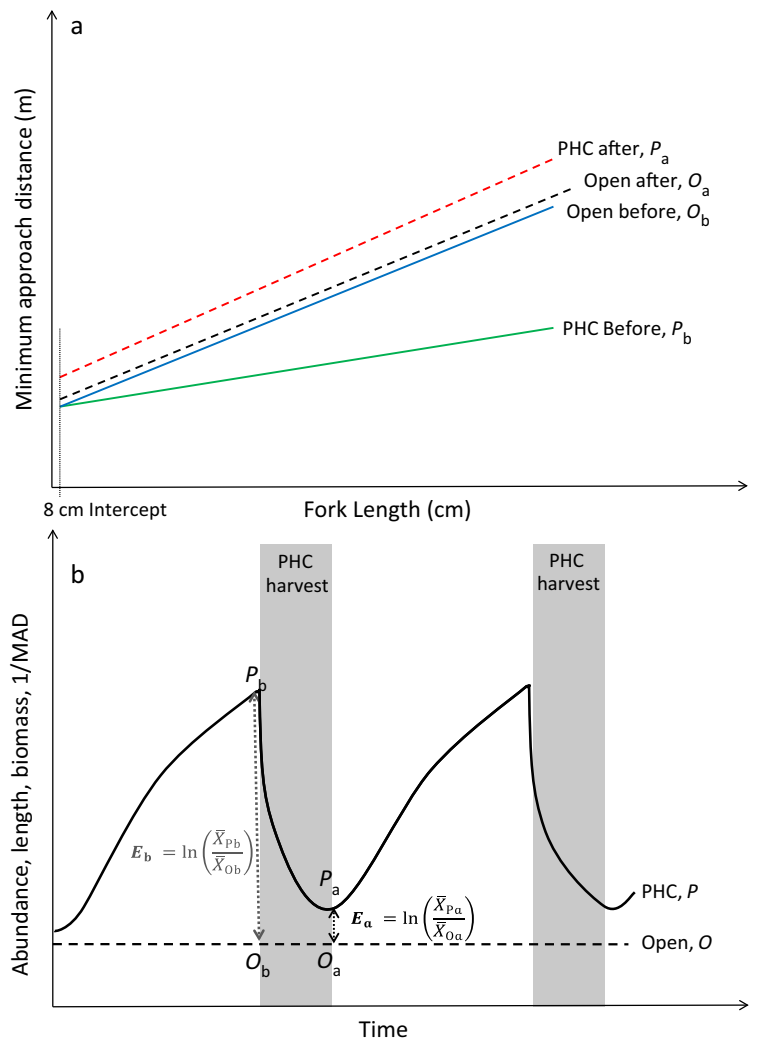

FIG. 1. (a) Conceptual diagram of the linear models of the minimum approach distance (MAD) to fish fork length relationship. Prior to harvest, the slope and intercept of the MAD to length relationship is expected to be lower within the periodic harvest closure (PHC; solid and green) than fished areas (solid and blue). After harvesting the slope and intercept of the MAD inside the PHC (dashed and red) is expected to be similar to fished areas (dashed and black), which is expected to remain unchanged. (b) Conceptual diagram of a theoretical harvest regime within a PHC $(P)$ and Open area $(O)$ before (b) and after (a) harvest events. Effect sizes are shown before $\left(E_{\mathrm{b}}\right.$, in grey) and after ( $E_{\mathrm{a}}$, in black) the harvest. [Colour figure can be viewed at wileyonlinelibrary.com]

Variance of the slope effect sizes were calculated as

$$
v_{m E_{b, i}}=\frac{\sigma_{P b, i}^{2}}{n_{P b, i} \times \beta_{P b, i}^{2}}+\frac{\sigma_{O b, i}^{2}}{n_{O b, i} \times \beta_{O b, i}^{2}}
$$

and

$$
v_{m E_{a, i}}=\frac{\sigma_{P a, i}^{2}}{n_{P a, i} \times \beta_{P a, i}^{2}}+\frac{\sigma_{O a, i}^{2}}{n_{O a, i} \times \beta_{O a, i}^{2}}
$$

where $v_{\mathrm{mE}_{b, i}}$ and $v_{\mathrm{mE}_{a, i}}$ are the variances associated with the slope effect sizes $m E_{b, i}$ and $m E_{a, i}, \sigma_{\mathrm{Pb}, \mathrm{i}}, \sigma_{\mathrm{Ob}, \mathrm{i}}, \sigma_{\mathrm{Pa}, \mathrm{i}}$, and $\sigma_{\mathrm{Oa}, \mathrm{i}}$ are the standard deviations associated with slopes $\beta_{\mathrm{Pb}, \mathrm{i}}, \beta_{\mathrm{Ob}, \mathrm{i}}, \beta_{\mathrm{Pa}, \mathrm{i}}$, and $\beta_{\mathrm{Oa}, \mathrm{i}}$, respectively, and $n_{P b, i}, n_{O b, i}$, $n_{P a, i}$, and $n_{O a, i}$ are the number of fish used to calculate each slope.

The intercept of each linear model (PHC before, open before, $\mathrm{PHC}$ after, and open after) was based on the average MAD of 8 -cm fish (Fig. 1a). An intercept of $8 \mathrm{~cm}$ was chosen because $8-\mathrm{cm}$ fish were the smallest that could be measured accurately and fish $<10 \mathrm{~cm}$ were not recorded from harvest catches. For each village $i$, the intercept effect size before the harvest $I E_{b, i}$, was calculated as the log-ratio of the Euclidean distance between the average MAD at $8 \mathrm{~cm}$ in the PHC before, $y_{x=8, P b, i}$ and the open before, $y_{x=8, O b, i}$, and after the harvest $I E_{a, i}$, the log-ratio in the PHC after, $y_{x}=8, P a, i$ and the open after, $y_{x}=8, O a, i$ (Fig. 1a)

$$
I E_{b, i}=\ln \left(\frac{y_{x=8, P b, i}}{y_{x=8, O b, i}}\right) \text { and } I E_{a, i}=\ln \left(\frac{y_{x=8, P a, i}}{y_{x=8, O a, i}}\right) .
$$

Variance of the intercept effect sizes were calculated as

$$
v_{I E_{b, i}}=\frac{\sigma_{P b, i}^{2}}{n_{P b, i} \times y_{x=8, P b, i}^{2}}+\frac{\sigma_{O b, i}^{2}}{n_{O b, i} \times y_{x=8, O b, i}^{2}}
$$

and

$$
v_{I E_{a, i}}=\frac{\sigma_{P a, i}^{2}}{n_{P a, i} \times y_{x=8, P a, i}^{2}}+\frac{\sigma_{O a, i}^{2}}{n_{O a, i} \times y_{x=8, O a, i}^{2}}
$$

where $v_{I E_{b, i}}$ and $v_{I E_{a, i}}$ are the variances associated with the intercept effect sizes $I E_{b, i}$ and $I E_{a, i}, \sigma_{P b, i}, \sigma_{O b, i}, \sigma_{P a, i}$, and $\sigma_{O a, i}$ are the standard deviations associated with $y_{x=8, P b, i}$, $y_{x=8, I O b, i}, y_{x=8, P a, i}$, and $y_{x=8, O a, i}$, respectively, and $n_{P b, i}$, $n_{O b, i}, n_{P a, i}$, and $n_{O a, i}$ are the number of fish used to calculate each slope.

Fig. 1a shows the expected results from a well-managed PHC that is impacted by an intense harvest event. PHC protection results in a negative slope effect size, shown by a decreased slope in the PHC before relative to the open before model. There is no difference in the intercepts before the harvest suggesting the decreased slope in the PHC before is due to a lower wariness of larger individuals. Post-harvest the slope of the PHC after has increased so it is comparable to the open after. Here, the harvest has impacted all sizes of fish because there has been an increase in slope and the intercept in the PHC after compared to the open after.

Abundance, length, and biomass. - For each village $i$, the effect size before the harvest $E_{b, i}$, was calculated as the log-ratio of the mean abundance, length, or biomass per replicate in the PHC before, $\bar{X}_{P b, i}$, and the open before, $\bar{X}_{O b, i}$, and after the harvest $E_{a, i}$, the log ratio in the PHC after, $\bar{X}_{P a, i}$, and the open after, $\bar{X}_{O a, i}$ (see Fig. 1b for conceptual diagram)

$$
E_{b, i}=\ln \left(\frac{\bar{X}_{P b, i}}{\bar{X}_{O b, i}}\right) \text { and } E_{a, i}=\ln \left(\frac{\bar{X}_{P a, i}}{\bar{X}_{O a, i}}\right)
$$

Variance of the effect sizes were calculated as

$$
v_{E_{b, i}}=\frac{\sigma_{P b, i}^{2}}{n_{P b, i} \times \bar{X}_{P b, i}^{2}}+\frac{\sigma_{O b, i}^{2}}{n_{O b, i} \times \bar{X}_{O b, i}^{2}}
$$


and

$$
v_{E_{a, i}}=\frac{\sigma_{P a, i}^{2}}{n_{P a, i} \times \bar{X}_{P a, i}^{2}}+\frac{\sigma_{O a, i}^{2}}{n_{O a, i} \times \bar{X}_{O a, i}^{2}}
$$

where $v_{E_{b j}}$ and $v_{E_{a j}}$ are the variances associated with the effect sizes $E_{b, i}$ and $E_{a, i}, \sigma_{P b, i}, \sigma_{O b, i}, \sigma_{P a, i}$, and $\sigma_{O a, i}$ are the standard deviations associated with the means $\bar{X}_{P b, i}$, $\bar{X}_{O b, i}, \bar{X}_{P a, i}$, and $\bar{X}_{O a, i}$, respectively, and $n_{P b, i}, n_{O b, i}, n_{P a, i}$, and $n_{O a, i}$ are the number of replicates used to calculate each mean.

Fig. 1b shows the expected results from a well-managed PHC that is impacted by intense harvest events. There is a significantly positive effect size before the harvest $\left(E_{b}\right)$, suggesting that PHC protection has increased the abundance/length/biomass and reduced fish wariness. The effect size after an intense harvest $\left(E_{a}\right)$ decreases making the PHC comparable to open areas.

Meta-analysis framework.-We used a random effects model, with a restricted maximum-likelihood estimator to assess the effectiveness of PHCs before and after harvests and test for heterogeneity using the effect sizes defined above. Meta-analyses were done using the package metafor (Viechtbauer 2010) in the R language for statistical computing (R Development Core Team 2014). Where a significant effect of protection and an impact of the harvest were detected at the pooled species level for wariness, abundance, length, or biomass, we explored the results of protection and harvest at the level of individual species.

\section{RESULTS}

Across the four villages and all focal species, a total of 4522 individuals were observed in the abundance data of which $79.3 \%$ were measured providing length, biomass, and MAD information for 3585 individuals.

\section{Wariness}

Before harvests, the slope of minimum approach distance (MAD)/fish length within PHCs was 25\% lower than in open areas, for the pooled targeted species across all villages (Fig. 2a). This was due to lower wariness of larger individuals within the PHC, with no difference in the intercepts before the harvest $(95 \%$ CI overlapping zero; Fig. 2b). This result was most evident in the Nakodu and Natokalau PHCs, where MAD increased with fish length for all targeted species and the non-targeted H. trimaculatus (Table 2, Fig. 3; Data S1). Before the harvest in Nakodu, the slope of MAD/fish length within PHCs was 37\% lower than in open areas for C. spilurus and $43 \%$ for Halichoeres hortulanus, while in Natokalau Scarus rivulatus was $55 \%$ lower in PHCs compared to open areas. This indicates a lower wariness of larger individuals for all three species within the PHCs, with no difference in the intercepts before harvests. a) Wariness (slope) b) Wariness (intercept)

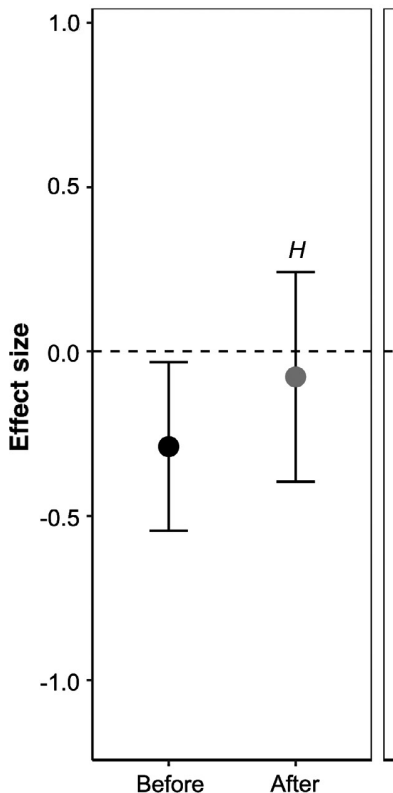

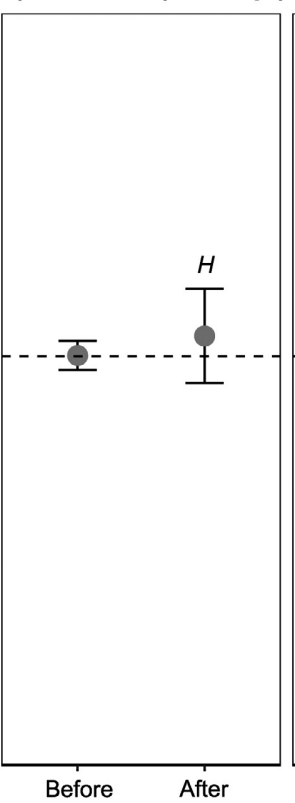

c) Abundance

d) Length

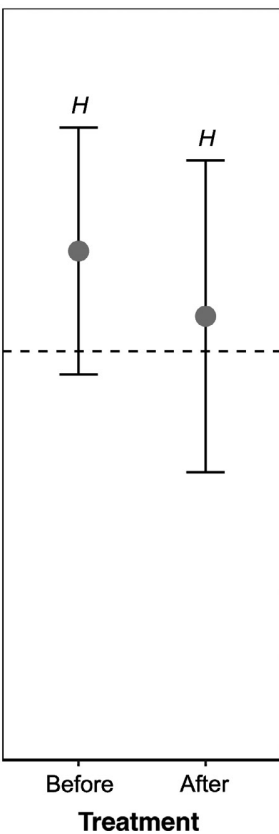

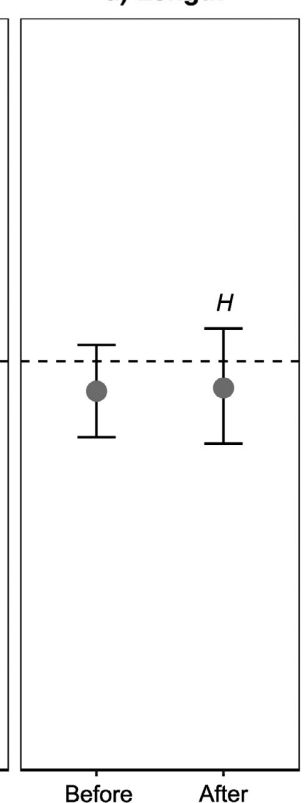

Before e) Biomass

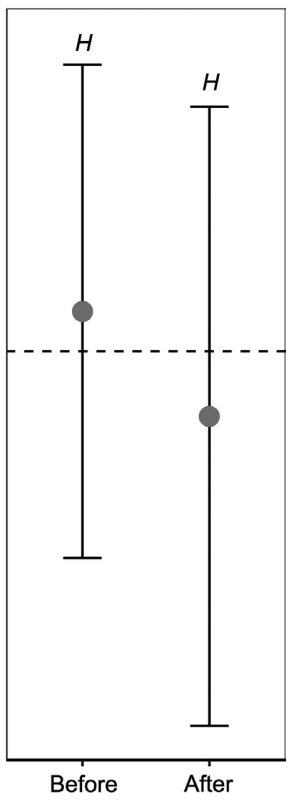

FIG. 2. PHC vs. Open area log-ratio effect sizes for the pooled targeted species across all villages before and after the harvest across (a, b) wariness, (c) abundance, (d) length, and (e) biomass metrics. Black dots represent results where the $95 \%$ confidence interval of the effect size does not overlap zero. The superscript $H$ indicates that significant heterogeneity $(H<0.05)$ was associated with the effect size. 
After the harvest, there was no difference in slope within PHCs compared to open areas in the pooled targeted species across all villages (Fig. 2a). This indicates an increase in the wariness of larger individuals within PHCs, with no difference in intercepts after the harvest (Fig. 2b). However, both the slope and intercept effects were heterogeneous, suggesting different impacts of the harvest on fish wariness between PHCs. After the harvest an increase in intercept was observed for pooled targeted species in Nakodu and Tuatua, indicating increased wariness across fish of all sizes (Table 2). In the Nakodu PHC, there was an increase in intercept for C. spilurus, and slope for C. spilurus, H. hortulanus and S. rivulatus, making wariness comparable or greater than open areas (Table 2, Fig. 3). This increased wariness occurred in larger individuals of $S$. rivulatus and $H$. Hortulanus within the Nakodu PHC, with no difference in the intercepts after the harvest. All sizes of $C$. spilurus were impacted by the harvest with a significant increase in the intercept of the PHC when compared to open areas after the harvest. In the Natokalau PHC, there was an increase in slope for C. spilurus after the harvest. The increase in wariness occurred in larger individuals, with no difference in the intercept after the harvest. For the nontarget species $H$. trimaculatus, there were no differences in slope or intercept between the Nakodu or Natokalau PHCs and open areas, before or after harvests.

\section{Abundance}

On average, there was no difference in the abundance of targeted species between PHCs and open areas, before or after harvests (Fig. 2c). However, this result was heterogeneous, suggesting variation across PHCs. Targeted species were $136 \%$ and $80 \%$ more abundant before and after the harvest, respectively, in the Nakodu PHC compared to areas open to fishing (Table 2). Significantly greater abundances of $C$. spilurus and S. rivulatus were recorded in the Nakodu PHC before the harvest ( $146 \%$ and $241 \%$ greater than open areas, respectively). S. rivulatus was the only species impacted by the harvest, with abundance only 5\% greater in the PHC compared to open areas after the harvest. There were no significant differences in the abundance of the non-target species $H$. trimaculatus in the Nakodu PHCs compared to open areas, before or after harvest (Table 2). There were no significant differences in the abundance of any targeted species or the non-target $H$. trimaculatus between the Natokalau PHC and open areas before the harvest. After the harvest there was an increase in S. rivulatus and a decrease in the non-target $H$. trimaculatus in the Natokalau PHC compared to open areas.

\section{Length}

On average, there was no difference in mean length of targeted species between PHCs and open areas, before or after harvests (Fig. 2d). However, the result after the harvest was heterogeneous, suggesting variation across PHCs. In the Natokalau PHC, the mean length of targeted species was $23 \%$ smaller than in areas open to fishing, after the harvest (Table 2). In the Nauouo PHC, the mean lengths of targeted species were smaller in areas open to fishing, both before and after the harvest.

The mean lengths of $C$. spilurus, S. rivulatus, and Scarus schlegeli in the Natokalau PHC were 18\%, 24\%,

TABLE 2. PHC vs. open area effect sizes for targeted species and non-target Halichoeres trimaculatus (NT) before and after the harvest across wariness, abundance, length, and biomass metrics.

\begin{tabular}{|c|c|c|c|c|c|c|c|c|c|c|}
\hline \multirow[b]{3}{*}{ Species } & \multicolumn{10}{|c|}{ Wariness } \\
\hline & \multicolumn{2}{|c|}{ Slope } & \multicolumn{2}{|c|}{ Intercept } & \multicolumn{2}{|c|}{ Abundance } & \multicolumn{2}{|c|}{ Length } & \multicolumn{2}{|c|}{ Biomass } \\
\hline & Before & After & Before & After & Before & After & Before & After & Before & After \\
\hline \multicolumn{11}{|l|}{ Nakodu } \\
\hline Targeted (pooled) & -37 & 22 & 2 & 16 & 136 & 80 & 1 & 12 & 194 & 164 \\
\hline Chlorurus spilurus & -37 & 28 & -1 & 12 & 146 & 119 & 3 & 9 & 219 & 196 \\
\hline Scarus rivulatus & -26 & 65 & 9 & -1 & 241 & 5 & 0 & 13 & 221 & 63 \\
\hline Halichoeres hortulanus & -43 & 62 & 7 & 5 & 40 & 42 & 6 & 28 & 95 & 215 \\
\hline Halichoeres trimaculatus (NT) & 118 & 13 & -9 & 12 & 40 & 24 & 6 & 12 & 80 & 83 \\
\hline \multicolumn{11}{|l|}{ Natokalau } \\
\hline Targeted (pooled) & -35 & -33 & -3 & -1 & 14 & 38 & -9 & -23 & 1 & -47 \\
\hline Chlorurus spilurus & -4 & -53 & -13 & -6 & -8 & -7 & -7 & -18 & -19 & -55 \\
\hline Scarus rivulatus & -55 & 11 & 5 & 1 & 1 & 64 & -6 & -24 & 13 & -41 \\
\hline Scarus schlegeli & 1 & -79 & -7 & 11 & 96 & 67 & -12 & -20 & 58 & -12 \\
\hline Halichoeres trimaculatus (NT) & 190 & -17 & -20 & -7 & 15 & -36 & -1 & 1 & 38 & -41 \\
\hline \multicolumn{11}{|l|}{ Nauouo } \\
\hline Targeted (pooled) & -19 & 13 & 1 & -9 & 28 & -39 & -24 & -17 & -51 & -70 \\
\hline \multicolumn{11}{|l|}{ Tuatua } \\
\hline Targeted (pooled) & -2 & -32 & 5 & 29 & 0 & -11 & 3 & 4 & 4 & 4 \\
\hline
\end{tabular}

Notes: Effect sizes (log-ratios) are back transformed and presented as the percentage of increase (or decrease) inside the PHC compared to outside. Percentages are shown in boldface type when the $95 \%$ confidence interval of the effect size did not overlap zero. 

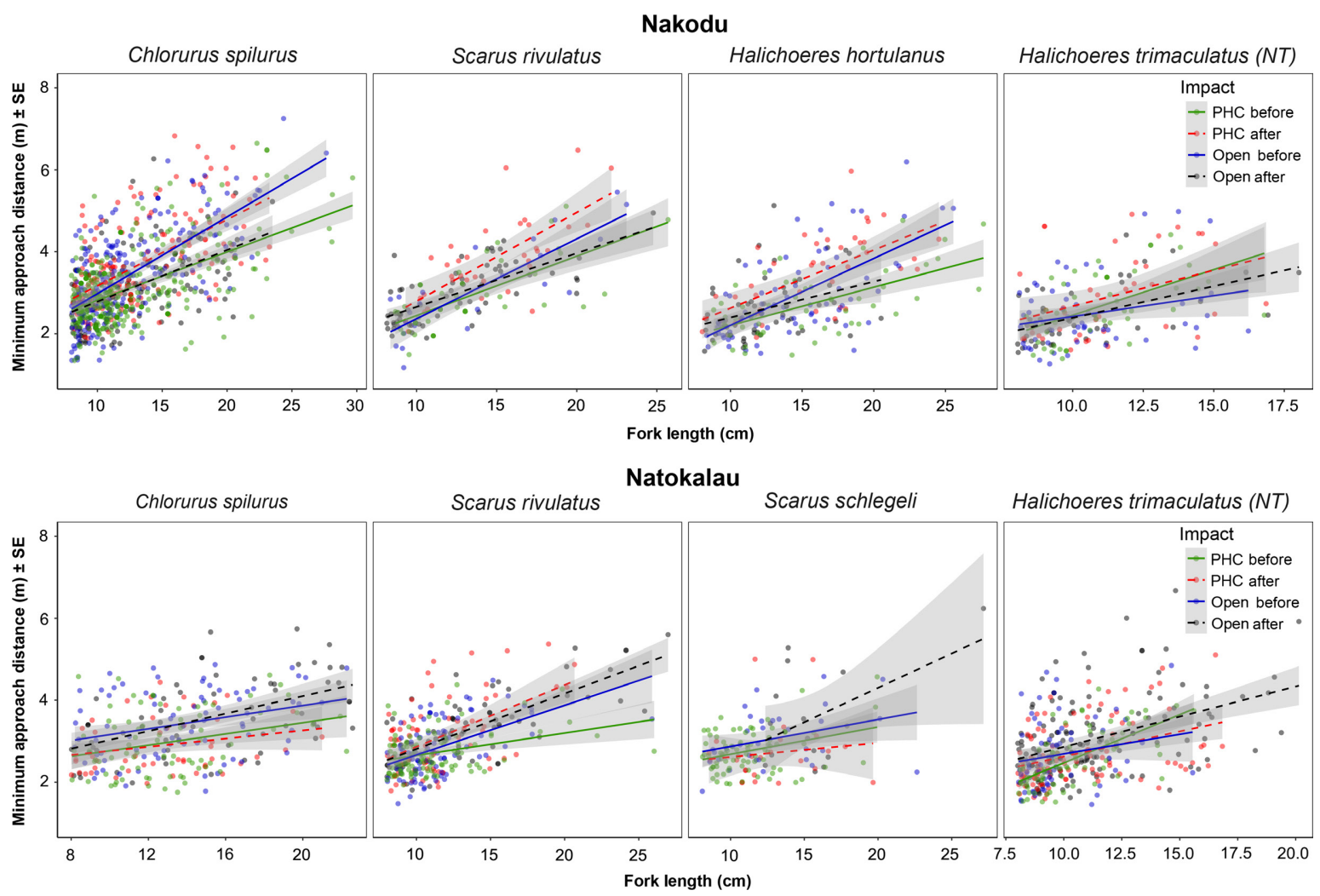

FIG. 3. Linear models for the PHC before (solid green line and dots), PHC after (dashed red line and dots), open before (solid blue line and dots), and open after (dashed black line and dots) for the three targeted and one non-targeted species H. trimaculatus (NT) in Nakodu and Natokalau villages. Gray shading shows SE. [Colour figure can be viewed at wileyonlinelibrary.com]

and $20 \%$ smaller than areas open to fishing after the harvest, respectively (Table 2). There was no difference in the mean length of the non-target species $H$. trimaculatus between the Natokalau PHC and open areas after the harvest.

\section{Biomass}

On average, there was no difference in the biomass of targeted species between PHCs and open areas, before or after harvests (Fig. 2e). This result was heterogeneous, suggesting variation across PHCs. In the Nakodu PHC, there was $194 \%$ greater biomass of targeted species before, and 164\% after, the harvest compared to areas open to fishing. At Nauouo, biomass was lower in the PHC compared to outside before and after the harvest.

Greater biomass of $C$. spilurus, $S$. rivulatus, and $H$. hortulanus was recorded in the Nakodu PHC before the harvest $(219 \%, 221 \%$ and $95 \%$ greater than open areas, respectively; Table 2). S. rivulatus was the only species to be impacted by the harvest with its biomass being reduced to $63 \%$ greater in the PHC compared to open areas, after the harvest. Greater biomass of the non-target $H$. trimaculatus was recorded in the PHC compared to open areas after the harvest. In the Natokalau PHC, there were no significant differences in biomass of all three targeted species when compared to open areas, before or after the harvest. There was a significant decrease in $\mathrm{H}$. trimaculatus within the Natokalau PHC compared to open areas, after the harvest.

\section{DisCusSION}

Diver operated stereo-video (stereo-DOV) provides a rapid assessment of fish wariness, which is sensitive to fishing pressure, while simultaneously collecting abundance, length, and biomass information. We observed an overall decrease in wary behavior of target fish within PHCs before harvesting and an increase in wary behavior due to harvests that contrasted with inconsistent results for abundance, length, and biomass of these species. Given these inconsistencies, we contend that wariness is the most sensitive and reliable indicator of changes to fishing pressure in areas where spearfishing and fish drives are common. However, a complete picture of impact may be best evaluated from examining a broad range of indicators when assessing the effects of fishing (Shin et al. 2005, Langlois et al. 2012, Nash and Graham 2016), highlighting the benefits of methods such as stereo-DOVs that provide a broad range of information.

While, the intensive pulse fishing associated with harvesting a PHC may not occur in fisheries that do not 
utilize this form of management, the consistent decrease in wariness associated with PHC protection suggests these results will be applicable to monitoring no-take marine reserves, given PHCs function similarly before they are opened to fishing. The potential for fisheries to alter social structures as a result of increased wariness, highlights the importance of understanding fish behavior for conservation and fisheries management (Bergseth et al. 2015). The use of stereo-DOVs to monitor no-take marine reserves will therefore not only provide useful information on traditional metrics to assess the impacts of fisheries management, but a rapid and comprehensive assessment of wariness that can potentially determine whether spearfishing is having an impact on behavior. Furthermore, pulse fishing events are likely to occur where no-take marine reserve management breaks down (Russ and Alcala 2003, McClanahan et al. 2006 b, Kulbicki et al. 2007), suggesting stereo-DOVs will be useful for monitoring fish under these circumstances. Protection benefits of PHCs in terms of abundance and biomass have been shown to increase as the size of a PHC increases (Goetze 2016). This suggests that the extent of wariness is likely to decrease as the size of a closure increases as less movement of fish is expected across boundaries and therefore less spill-in of wary behavior (Januchowski-Hartley et al. 2015).

We observed a positive biomass response to PHC protection in all three target species in one of the four study villages (Nakodu), which is partly due to high compliance, but also to Nakodu having the longest period of closure ( $3 \mathrm{yr}$ ) across all villages. In contrast, a consistent response was not observed in abundance or length. This is likely because fish weight is a power function of length, so a few larger individuals can have a large effect on biomass but not necessarily mean length or abundance. It can take several years for fish to attain large weights, so although biomass is sensitive to increases in fishing pressure it may respond more slowly to protection (Russ and Alcala 2004, Russ et al. 2005, McClanahan et al. 2007). Conversely, in the Natokalau PHC, there was a negative harvest impact on the mean length of all three targeted species, but not abundance or biomass, highlighting the complex relationship between abundance and biomass and the need to investigate change across the entire size spectrum (Rochet and Trenkel 2003, Trenkel and Rochet 2003, Dulvy et al. 2004).

PHCs are now the most widely adopted fisheries management strategy across Melanesia, partially due to their promotion by conservation and natural resource management organizations. Our results show that PHCs are capable of increasing catch efficiency potential by reducing the wariness of targeted fishes. Before harvesting, the most common targeted species were less wary within all PHCs, with similar results reported in case studies of PHCs in Papua New Guinea and Vanuatu (Feary et al. 2011, Januchowski-Hartley et al. 2014). However, the extent of wariness was not of the same magnitude across PHCs; the two PHCs where fish were significantly less wary recorded greatest harvest efficiencies, suggesting the decrease in wariness translated into greater catch efficiency. The Nakodu and Natokalau PHCs had low and high fishing pressure outside of their boundaries respectively, suggesting fishing pressure across both villages was sufficient to reduce wariness. We recorded a rapid increase in targeted fish wariness after short (1-4d), harvest events, similar to results in Vanuatu, where an increase in the wariness of Acanthuridae occurred after just $3 \mathrm{~d}$ of harvesting (JanuchowskiHartley et al. 2014). PHCs are thus potentially effective for taming fish, which may translate into short-term increases in harvest efficiency. However, with reductions in wariness possibly facilitating overfishing, longer closure periods may be needed to ensure increases in abundance, length and biomass (e.g., McClanahan et al. 2007). While our results suggest that wary behavior can increase rapidly due to pulse fishing events further effort is required to investigate how long wary behavior will persist once an area is closed to fishing. Changes in behavior observed here were from closures of 1 and $3 \mathrm{yr}$ and previous studies found an decrease in wariness after six months of closure (Januchowski-Hartley et al. 2014), suggesting rapid increases in wariness may take a long time to recover.

In Nakodu and Natokalau we observed the greatest effect of PHC protection on the wariness of the pooled targeted species. In Nakodu, the harvest resulted in increased wariness across all sizes of the three targeted species. This is most likely due to the high intensity and method of harvesting at Nakodu, where a fish-drive strategy was utilized, involving up to 70 fishers and "doubling up" of a gill net so that fish as small as $10 \mathrm{~cm}$ were caught. Conversely, in Natokalau, harvest intensity was lower and spearfishing was the main fishing method used so only larger individuals were impacted. Fish-drives appear particularly effective at increasing wariness across a broad size range, due to the indiscriminate targeting of fish and/or degradation of habitat (Jennings and Polunin 1996a) and subsequent increase in anti-predator response behavior (McCormick and Lönnstedt 2013). In contrast, relatively light and infrequent harvests potentially only affect wariness of larger individuals that are expected to be more sensitive to threats (Stankowich and Blumstein 2005, Cooper and Frederick 2007). Recent studies have highlighted that similar relationships exists in areas where line fishing is common (Alós et al. 2012, 2015).

The size of an individual is a major driver of antipredator behavior across taxa, and has a generally positive relationship with wariness (Stankowich and Blumstein 2005). The positive relationship between MAD and fish length for targeted and non-target species in Nakodu and Natokalau is consistent with both theoretical (Ydenberg and Dill 1986, Cooper and Frederick 2007) and empirical studies of coral reef fishes (Gotanda et al. 2009, Januchowski-Hartley et al. 2015, Bergseth et al. 2016). However, the relationship between size and MAD was generally stronger for targeted species. 
Reduced threats from natural predators can alter behavior in fish (Madin et al. 2010), though reduced numbers of large piscivores on coral reefs, both in Fiji (Jennings and Polunin 1997, Dulvy et al. 2004, Goetze et al. 2011) and more generally (Myers and Worm 2003), suggests that the primary source of predation threat experienced by coral reef fishes post-recruitment is fishing activity.

Stereo-DOVs can rapidly provide large amounts of behavioral data, by using a proxy for fish wariness (MAD). MAD can be extracted through a simple change in video analysis (Lindfield et al. 2014), without compromising assessments of abundance and length, providing a basis for collection of behavioral data from archived images for comparison with current and future studies. While, the adoption of stereo video methods is often inhibited by expensive video equipment, they are now becoming less expensive, more readily available and smaller, increasing their appeal for marine monitoring. In contrast to underwater visual census, stereo-DOV provides a permanent record of imagery that can be rapidly collected in the field and reviewed at any time, which somewhat offsets the extensive time needed to complete video analysis (Holmes et al. 2013, Goetze et al. 2015). This also eliminates concerns over increased bias associated with the greater time needed to make distance estimates using UVC (Watson et al. 1995, Kulbicki and Sarramégna 1999). Given the benefits of increases replication of behavioral data, simultaneous collection of a wide range of metrics and continued reduction in gear costs as technology develops, stereo-DOVs are an increasingly attractive tool for the assessment of fisheries management and conservations strategies.

Behavioral data may be particularly important for scientists to inform monitoring programs, given that we show wariness is more sensitive to changes in fishing pressure when compared to abundance, length and biomass. For example, the impacts of poaching are often difficult to quantify (Bergseth et al. 2015), and here the two villages showing discernible behavioral effects were associated with good compliance. It is possible that further research can use well enforced no-take marine reserves to provide a baseline of wary behavior and use this to discern whether poaching from spear-fishing is occurring elsewhere. However, the applicability of MAD in assessing wariness needs to be investigated over a broader range of fishing types, pressures and management strategies and the extent of movement of wary behavior across boundaries accounted for in order to quantify poaching.

\section{ACKNOWLEDGMENTS}

Funding was provided from the School of Plant Biology at The University of Western Australia (UWA) and the David and Lucile Packard Foundation (grant 2012-38137). This manuscript was drafted during a workshop funded by the UWA Oceans Institute as part of an Emerging Leaders Grant. We thank WCS and UWA Marine Ecology Group staff and local community members for field assistance, and Paul Iskov during the workshop. Thanks to Tom Holmes and Rebecca Weeks for reviewing the manuscript.

\section{Literature Cited}

Alós, J., M. Palmer, and R. Arlinghaus. 2012. Consistent selection towards low activity phenotypes when catchability depends on encounters among human predators and fish. PLoS ONE 7:e48030.

Alós, J., A. Puiggrós, C. Díaz-Gil, M. Palmer, R. Rosselló, and R. Arlinghaus. 2015. Empirical evidence for species-specific export of fish naïveté from a no-take marine protected area in a coastal recreational hook and line fishery. PLoS ONE 10:e0135348.

Bartlett, C. Y., C. Manua, J. Cinner, S. Sutton, R. Jimmy, R. South, J. Nilsson, and J. Raina. 2009. Comparison of outcomes of permanently closed and periodically harvested coral reef reserves. Conservation Biology 23:1475-1484.

Bergseth, B. J., G. R. Russ, and J. E. Cinner. 2015. Measuring and monitoring compliance in no-take marine reserves. Fish and Fisheries 16:240-258.

Bergseth, B. J., D. H. Williamson, A. J. Frisch, and G. R. Russ 2016. Protected areas preserve natural behaviour of a targeted fish species on coral reefs. Biological Conservation 198:202-209.

Blanchard, R. J., D. C. Blanchard, J. Rodgers, and S. M. Weiss. 1991. The characterization and modelling of antipredator defensive behavior. Neuroscience and Biobehavioral Reviews $14: 463-472$.

Brown, G. E. 2003. Learning about danger: chemical alarm cues and local risk assessment in prey fishes. Fish and Fisheries 4:227-234

Cakacaka, A., S. D. Jupiter, D. P. Egli, and W. Moy. 2010. Status of fin fisheries in a Fijian traditional fishing ground, Kubulau District, Vanua Levu. Wildlife Conservation Society, Suva, Fiji.

Cinner, J., M. J. Marnane, T. R. McClanahan, and G. R. Almany. 2006. Periodic closures as adaptive coral reef management in the Indo-Pacific. Ecology and Society 11:31.

Cinner, J. E., et al. 2012. Comanagement of coral reef socialecological systems. Proceedings of the National Academy of Sciences USA 109:5219-5222.

Claudet, J., D. Pelletier, J.-Y. Jouvenel, F. Bachet, and R. Galzin. 2006. Assessing the effects of marine protected area (MPA) on a reef fish assemblage in a northwestern Mediterranean marine reserve: Identifying community-based indicators. Biological Conservation 130:349-369.

Cohen, P. J., and S. J. Foale. 2013. Sustaining small-scale fisheries with periodically harvested marine reserves. Marine Policy 37:278-287.

Cooper, W. E., and W. G. Frederick. 2007. Optimal flight initiation distance. Journal of Theoretical Biology 244:59-67.

De Klerk, P., and M. Gatto. 1981. Some remarks on periodic harvesting of a fish population. Mathematical Biosciences 56:47-69.

Dulvy, N. K., R. P. Freckleton, and N. V. C. Polunin. 2004. Coral reef cascades and the indirect effects of predator removal by exploitation. Ecology Letters 7:410-416.

Feary, D. A., J. E. Cinner, N. A. Graham, and F. A. Januchowski-Hartley. 2011. Effects of customary marine closures on fish behavior, spear-fishing success, and underwater visual surveys. Conservation Biology 25:341-349.

Froese, R., and D. Pauly. 2015. FishBase. http://www.fishbase. org/

Game, E. T., M. Bode, E. McDonald-Madden, H. S. Grantham, and H. P. Possingham. 2009. Dynamic marine protected 
areas can improve the resilience of coral reef systems. Ecology Letters 12:1336-1346.

Goetze, J. S., T. J. Langlois, D. P. Egli, and E. S. Harvey. 2011. Evidence of artisanal fishing impacts and depth refuge in assemblages of Fijian reef fish. Coral Reefs 30:507-517.

Goetze, J. S., S. D. Jupiter, T. J. Langlois, S. K. Wilson, E. S. Harvey, T. Bond, and W. Naisilisili. 2015. Diver operated video most accurately detects the impacts of fishing within periodically harvested closures. Journal of Experimental Marine Biology and Ecology 462:74-82.

Goetze, J., T. Langlois, J. Claudet, F. Januchowski-Hartley, and S. D. Jupiter. 2016. Periodically harvested closures require full protection of vulnerable species and longer closure periods. Biological Conservation 203:67-74

Goetze, J. S. 2016. The effectiveness of periodically harvested closures as a fisheries management strategy. http:// research-repository.uwa.edu.au/files/11488353/THESIS_ DOCTOR_OF_PHILOSOPHY_GOETZE_Jordan_Scott_ 2016.pdf

Gotanda, K. M., K. Turgeon, and D. L. Kramer. 2009. Body size and reserve protection affect flight initiation distance in parrotfishes. Behavioral Ecology and Sociobiology 63: $1563-1572$.

Govan, H., et al. 2009. Status and potential of locally-managed marine areas in the South Pacific: meeting nature conservation and sustainable livelihood targets through wide-spread implementation of LMMAs. SPREP/WWF/WorldFishReef base/CRISP, Suva, Fiji.

Graham, N. A. J., N. K. Dulvy, S. Jennings, and N. V. C. Polunin. 2005. Size-spectra as indicators of the effects of fishing on coral reef fish assemblages. Coral Reefs 24:118-124.

Gurevitch, J., and L. V. Hedges. 1999. Statistical issues in ecological meta-analyses. Ecology 80:1142-1149.

Hart, D. R. 2003. Yield-and biomass-per-recruit analysis for rotational fisheries, with an application to the Atlantic sea scallop (Placopecten magellanicus). Fishery Bulletin 101: 44-57.

Harvey, E. S., and M. R. Shortis. 1998. Calibration stability of an underwater stereo-video system: implications for measurement accuracy and precision. Marine Technology Society Journal 32:3-17.

Harvey, E. S., D. Fletcher, M. Shortis, and G. Kendrick. 2004. A comparison of underwater visual distance estimates made by scuba divers and a stereo-video system: implications for underwater visual census of reef fish abundance. Marine and Freshwater Research 55:573-580.

Harvey, E. S., J. S. Goetze, B. McLaren, T. Langlois, and M. R. Shortis. 2010. Influence of range, angle of view, image resolution and image compression on underwater stereo-video measurements: high-definition and broadcast-resolution video cameras compared. Marine Technology Society Journal 44:75-85.

Hedges, L. V., J. Gurevitch, and P. S. Curtis. 1999. The metaanalysis of response ratios in experimental ecology. Ecology 80:1150-1156.

Holmes, T. H., S. K. Wilson, M. J. Travers, T. J. Langlois, R. D. Evans, G. I. Moore, R. A. Douglas, G. Shedrawi, E. S. Harvey, and K. Hickey. 2013. A comparison of visual-and stereo-video based fish community assessment methods in tropical and temperate marine waters of Western Australia. Limnology and Oceanography: Methods 11:337-350.

Januchowski-Hartley, F. A., N. A. J. Graham, D. A. Feary, T. Morove, and J. E. Cinner. 2011. Fear of fishers: human predation explains behavioral changes in coral reef fishes. PLoS ONE 6:e22761.

Januchowski-Hartley, F. A., K. L. Nash, and R. J. Lawton. 2012. Influence of spear guns, dive gear and observers on estimating fish flight initiation distance on coral reefs. Marine Ecology Progress Series 469:113.

Januchowski-Hartley, F. A., J. E. Cinner, and N. A. J. Graham. 2014. Fishery benefits from behavioural modification of fishes in periodically harvested fisheries closures. Aquatic Conservation: Marine and Freshwater Ecosystems 24:777-790.

Januchowski-Hartley, F. A., N. A. J. Graham, J. E. Cinner, and G. R. Russ. 2015. Local fishing influences coral reef fish behavior inside protected areas of the Indo-Pacific. Biological Conservation 182:8-12.

Jennings, S., and N. V. C. Polunin. 1996a. Impacts of fishing on tropical reef ecosystems. Ambio 25:44-49.

Jennings, S., and N. V. C. Polunin. 1996b. Effects of fishing effort and catch rate upon the structure and biomass of Fijian reef fish communities. Journal of Applied Ecology 33: $400-412$.

Jennings, S., and N. V. C. Polunin. 1997. Impacts of predator depletion by fishing on the biomass and diversity of nontarget reef fish communities. Coral Reefs 16:71-82.

Jupiter, S. D., and D. P. Egli. 2011. Ecosystem-based management in Fiji: successes and challenges after five years of implementation. Journal of Marine Biology 2011:e940765.

Jupiter, S. D., R. Weeks, A. P. Jenkins, D. P. Egli, and A. Cakacaka. 2012. Effects of a single intensive harvest event on fish populations inside a customary marine closure. Coral Reefs 31:321-334.

Kulbicki, M., and S. Sarramégna. 1999. Comparison of density estimates derived from strip transect and distance sampling for underwater visual censuses: a case study of Chaetodontidae and Pomacanthidae. Aquatic Living Resources 12:315-325.

Kulbicki, M., S. Sarramégna, Y. Letourneur, L. Wantiez, R. Galzin, G. Mou-Tham, C. Chauvet, and P. Thollot. 2007. Opening of an MPA to fishing: Natural variations in the structure of a coral reef fish assemblage obscure changes due to fishing. Journal of Experimental Marine Biology and Ecology 353:145-163.

Langlois, T. J., E. S. Harvey, and J. J. Meeuwig. 2012. Strong direct and inconsistent indirect effects of fishing found using stereo-video: Testing indicators from fisheries closures. Ecological Indicators 23:524-534.

Langlois, T. J., S. J. Newman, M. Cappo, E. S. Harvey, B. M. Rome, C. L. Skepper, and C. B. Wakefield. 2015. Length selectivity of commercial fish traps assessed from in situ comparisons with stereo-video: Is there evidence of sampling bias? Fisheries Research 161:145-155.

Lindfield, S. J., E. S. Harvey, J. L. McIlwain, and A. R. Halford. 2014. Silent fish surveys: bubble-free diving highlights inaccuracies associated with SCUBA-based surveys in heavily fished areas. Methods in Ecology and Evolution 5:1061-1069.

Macintyre, M., and S. Foale. 2007. Land and marine tenure, ownership, and new forms of entitlement on Lihir: changing notions of property in the context of a goldmining project. Human Organization 66:49-59.

MacNeil, M. A., et al. 2015. Recovery potential of the world's coral reef fishes. Nature 520:341-344.

Madin, E. M. P., S. D. Gaines, J. S. Madin, and R. R. Warner. 2010. Fishing indirectly structures macroalgal assemblages by altering herbivore behavior. American Naturalist 176:785-801.

McClanahan, T. R., M. J. Marnane, J. E. Cinner, and W. E. Kiene. 2006a. A comparison of marine protected areas and alternative approaches to coral-reef management. Current Biology 16:1408-1413.

McClanahan, T. R., E. Verheij, and J. Maina. 2006b. Comparing the management effectiveness of a marine park and a multiple-use collaborative fisheries management area in East Africa. Aquatic Conservation: Marine and Freshwater Ecosystems 16:147-165. 
McClanahan, T. R., N. A. Graham, J. M. Calnan, and M. A. MacNeil. 2007. Toward pristine biomass: reef fish recovery in coral reef marine protected areas in Kenya. Ecological Applications 17:1055-1067.

McCormick, M. I., and O. M. Lönnstedt. 2013. Degrading habitats and the effect of topographic complexity on risk assessment. Ecology and Evolution 3:4221-4229.

Meyer, C. G., Y. P. Papastamatiou, and T. B. Clark. 2010. Differential movement patterns and site fidelity among trophic groups of reef fishes in a Hawaiian marine protected area. Marine Biology 157:1499-1511.

Myers, R. A., and B. Worm. 2003. Rapid worldwide depletion of predatory fish communities. Nature 423:280-283.

Nash, K. L., and N. A. J. Graham. 2016. Ecological indicators for coral reef fisheries management. Fish and Fisheries 17:1029-1054.

Nash, K. L., J. Q. Welsh, N. A. Graham, and D. R. Bellwood. 2015. Home-range allometry in coral reef fishes: comparison to other vertebrates, methodological issues and management implications. Oecologia 177:73-83.

Osenberg, C. W., O. Sarnelle, S. D. Cooper, and R. D. Holt. 1999. Resolving ecological questions through meta-analysis: goals, metrics, and models. Ecology 80:1105-1117.

Plagányi, É. E., T. Skewes, N. Murphy, R. Pascual, and M. Fischer. 2015. Crop rotations in the sea: Increasing returns and reducing risk of collapse in sea cucumber fisheries. Proceedings of the National Academy of Sciences USA 112:6760-6765.

R Development Core Team. 2015. R: a language and environment for statistical computing (version 3.2.2). $\mathrm{R}$ foundation for statistical computing, Vienna, Austria. https://www. Rproject.org/

Rochet, M. J., and V. M. Trenkel. 2003. Which community indicators can measure the impact of fishing? A review and proposals. Canadian Journal of Fisheries and Aquatic Sciences 60:86-99.
Russ, G. R., and A. C. Alcala. 2003. Marine reserves: Rates and patterns of recovery and decline of predatory fish, 1983-2000. Ecological Applications 13:1553-1565.

Russ, G. R., and A. C. Alcala. 2004. Marine reserves: long-term protection is required for full recovery of predatory fish populations. Oecologia 138:622-627.

Russ, G. R., B. Stockwell, and A. C. Alcala. 2005. Inferring versus measuring rates of recovery in no-take marine reserves. Marine Ecology Progress Series 292:1-12.

Shedrawi, G., E. S. Harvey, D. L. McLean, J. Prince, L. M. Bellchambers, and S. J. Newman. 2014. Evaluation of the effect of closed areas on a unique and shallow water coral reef fish assemblage reveals complex responses. Coral Reefs 33:579-591.

Shin, Y.-J., M.-J. Rochet, S. Jennings, J. G. Field, and H. Gislason. 2005. Using size-based indicators to evaluate the ecosystem effects of fishing. ICES Journal of Marine Science: Journal du Conseil 62:384-396.

Stankowich, T., and D. T. Blumstein. 2005. Fear in animals: a meta-analysis and review of risk assessment. Proceedings of the Royal Society B 272:2627-2634.

Trenkel, V. M., and M.-J. Rochet. 2003. Performance of indicators derived from abundance estimates for detecting the impact of fishing on a fish community. Canadian Journal of Fisheries and Aquatic Sciences 60:67-85.

Valderrama, D., and J. L. Anderson. 2007. Improving utilization of the Atlantic sea scallop resource: an analysis of rotational management of fishing grounds. Land Economics 83:86-103.

Viechtbauer, W. 2010. The metafor package: a meta-analysis package for R. http://www.metafor-project.org/doku.php/ metafor

Watson, R. A., G. M. Carlos, and M. A. Samoilys. 1995. Bias introduced by the non-random movement of fish in visual transect surveys. Ecological Modelling 77:205-214.

Ydenberg, R. C., and L. M. Dill. 1986. The economics of fleeing from predators. Advances in the Study of Behavior 16:229-249.

SUPPORTING INFORMATION

Additional supporting information may be found in the online version of this article at http://onlinelibrary.wiley.com/ doi/10.1002/eap.1511/full

\section{Data Availability}

Data associated with this paper is available as the Fiji Periodically Harvested Closures Project data in the GlobalArchive repository at http://146.118.103.240/geodata/explore/ 